\title{
Characterization of Resilient Adolescents in the Context of Parental Unemployment
}

\begin{abstract}
This research analyzes a group of Spanish adolescents at high risk of adversity -conceptualized as living in households with no employed parent- in one of the countries where unemployment rates have risen significantly due to the recent economic recession. The objective was to identify sociodemographic and contextual factors that promote resilience in this context. Using the Extreme Group Approach and the theoretical framework of resilience, two groups of adolescents living in households with no employed parent were selected from the HBSC-2014 edition in Spain depending on their adaptive response to the risk, measured by a global health score. Therefore, from a total sample of 1,336 adolescents at high risk (living in households with no employed parent), 290 resilient adolescents (those who presented the highest scores in their global health score) and 618 maladaptive adolescents (those presenting lower scores in their global health score) were selected, resulting in a final sample composed of 908 adolescents aged 11-18 years old $(M=15.2 ; D T=2.18)$, with a balanced representation of boys and girls. Results showed that support from, and satisfaction with, family and friend relationships, as well as support from classmates and teachers, and satisfaction with the school environment, are protective factors that can foster resilience when facing adversity provoked by parental unemployment and its negative consequences for adolescent health. Intervention programs aimed at reducing the negative impact of parental unemployment on adolescent health should consider these contextual factors, as well as individual factors such as age or sex.
\end{abstract}

Keywords: parental unemployment, adolescence, resilience, health, individual factors, contextual factors 


\section{Introduction}

An increase in economic problems is related to lower rates of wellbeing and a rise in common mental disorders, with unemployment representing an important risk factor for mental health (Gili et al. 2014; Rajmil et al. 2015). In a meta-analysis conducted by Paul and Moser (2009), findings demonstrated that not only is there a relationship between unemployment and mental health but also a causal negative effect with a moderate effect size, on average. Furthermore, unemployment not only affects the unemployed person but also their partner and their adolescent children (Bubonya et al. 2014). For example, Baxter et al. (2013) found that joblessness and working short part-time hours, compared to working full-time/long part-time hours, were related to lower levels of wellbeing for both parents and children. More specifically, several studies identify a relationship between parental unemployment and adolescents' psychosomatic symptoms and chronic illnesses (Reinhardt Pedersen et al. 2005), poor subjective health (Sleskova et al. 2006) or a rise in hospital admissions (Mörk et al. 2014).

Several studies by Elder (Elder and Caspi 1988; Elder 1994; Elder et al. 1985) offer the life course perspective, which emphasizes the interaction between external economic changes (e.g. economic recession or rising unemployment rates) and the internal family experience, focusing on mediating factors through which economic hardship can negatively affect child development, including family relationships, amongst other aspects. This was later developed into the family stress model which examines the impact of unemployment on family relationships, highlighting the negative effect that parents have on their relationship with their children, and consequently on their children's health, when they are less nurturing or more distressed (Conger and Donnellan 2007; Conger et al. 2010; Whitbeck et al. 1997). Along these lines, recent studies have focused on factors that can moderate the negative impact of parental unemployment on adolescent health. For example, in a study by Frasquilho et al. (2017), individual factors such as sex, socioeconomic status, or satisfaction with family relationships were found to moderate the relationship between parental unemployment and adolescent wellbeing. Specifically, results demonstrated that adolescent girls with low socioeconomic status and low family satisfaction were the most affected by parental unemployment. 
Moreover, other studies have emphasized how positive family relationships can buffer the negative impact of financial pressure and foster positive adaptation to economic adversity (Conger et al. 1992; Neppl et al. 2015). Along the same lines, an association has been found between family support, friend support (Williams and Anthony 2015), or the student's perception of their school environment which includes feelings of belonging and teacher connectedness (García-Moya et al. 2015; Fenton et al. 2010; García-Moya et al. 2014)-, and adolescent health and wellbeing.

The present research analyses individual and contextual factors that can promote adolescent health and wellbeing in the context of parental unemployment based on the resilience model. Several definitions of the concept (Olsson et al. 2003; Luthar et al. 2015), as well as various scales (Connor and Davidson 2003; Wagnild and Young 1993; Friborg et al. 2005), have been proposed to measure resilience. A previous study by Bacikova-Sleskova et al. (2015) which also analyzed resilience as a moderator between parental unemployment and adolescent health concluded that resilience did not reduce the negative impact of unemployment. However, in the cited research, resilience was considered as an individual trait whereas by contrast the present research considers resilience to be a dynamic process exposure to an adverse event and the subsequent manifestation of positive adjustment outcomes (Luthar and Cicchetti 2000)- and is therefore evaluated as healthy or adaptive functioning when facing adverse life experiences.

Low socioeconomic status has been classified as an adverse experience for adolescents (Buckner et al. 2003) and parental unemployment has been described as a stressful situation that especially affects the children (Ström 2003), furthermore showing the negative effects increase as children age (Komarovsky 2004). Therefore, in the present research adversity is conceptualised as the situation of adolescents living in households with no employed parent. Rising unemployment has been specifically highlighted as one of the most frequent consequences of the economic recession, with Spain being one of the most severely affected countries. Following Eurostat data (2016), unemployment rates have risen from $8.5 \%$ in 2006 to $19.9 \%$ in 2010 , and further increased to $24.5 \%$ in 2014 . Although some studies have found that mother's unemployment has a low or no significant effect on adolescent wellbeing (Piko and Fitzpatrick 2001; Bacikova-Sleskova et al. 2011), other research shows that adolescents with both parents unemployed present poorer health compared to those with only one unemployed parent (Reinhardt Pedersen et al. 2005). 
Furthermore, considering resilience as positive or healthy adaptation when dealing with an adverse event (Bonanno 2004; Bonanno et al. 2011), we selected a global health score (GHS) as an indicator of positive adaptation. This score is based on four key measures of adolescent health that address their physical and psychological wellbeing: self-rated health, psychosomatic complaints, healthrelated quality of life, and life satisfaction. The global health score has shown good psychometric properties (Ramos et al. 2012) and has been employed as a measure of adaptive functioning in previous resilience research (Moreno et al. 2016a).

Based on this conceptual framework - and following the classification proposed by Tiet and Huizinga (2002) - the present study defines two groups of individuals: resilient (adolescents who, despite living in households with no employed parent, present the highest GHS), and maladaptive (adolescents with the same exposure to adversity who present the lowest GHS). Using the Extreme Groups Approach (EGA) -tercile splits to categorize subjects into three groups (Preacher et al. 2005)-, this study selected adolescents living in households with no employed parent and divided them into terciles acording to their GHS. Despite this procedure's possible limitations, it allows subjects to be categorized into different groups according to conceptual definitions (DeCoster et al. 2009), for example selecting the maladaptive and resilient adolescents (Moreno et al. 2016a).

This study considers resilience to be a process of interaction between risk and the protective factors that can mitigate the negative effects of risk exposure (Rutter 1999). Individual, family and community factors (Southwick et al. 2014) have been identified as determinants of resilience, therefore we analyze sociodemographic factors and others related to family, friend and school contexts, in order to identify their capacity to foster resilience in the context of parental unemployment.

\section{Method}

\section{Participants}

Participants consisted of a representative sample of school-aged children aged 11-18 years old who participated in the 2014 Spanish edition of the Health Behaviour in School-aged Children (HBSC) study. The sample was selected through random multi-stage sampling stratified by conglomerates, considering habitat (rural or urban) and type of school (public or private). In addition, the Spanish data was nationally representative by age and region (Moreno et al. 2016b). Using this procedure, the Spanish HBSC-2014 survey contemplated a total sample of 31,058 adolescents. 
For the present research two groups of adolescents were selected from the total sample according to the responses obtained in two variables: parental unemployment and the Global Health Score (GHS, which is described in more details in the instruments section). In addition, terciles were used to identify adolescents presenting the highest, medium and lowest scores in the scale for GHS. To select the two groups of adolescents that were examined and compared in the present research, in the first stage only those adolescents living in households with no employed parent ( $5.7 \%$ of the total sample; 1,773 adolescents) were selected. In a second stage, this group was divided into terciles according to their rates in the GHS, thus reducing the sample to 1,336 adolescents who responded to all the necessary items to calculate their GHS. As expected, the sample comprised only on adolescents living in houses with no employed parent showed unequal distribution in the GHS: 618 adolescents in the lower tercile, 428 adolescents in the middle tercile, and only 290 adolescents in the highest tercile. Only the extreme groups were selected for this study thus resulting in a final sample of 908 adolescents $(51.5 \%$ were girls $)$ aged 11-18 years old $(M=15.2 ; D T=2.18)$.

\section{Instruments}

This study used the 2014 edition of the Spanish HBSC questionnaire, which includes questions about adolescent lifestyles, developmental contexts and positive health. Firstly, two specific measures were used to classify adolescents into groups:

- Parental employment status: this variable is created after crossing two questions -"Does your father have a job?" and 'Does your mother have a job?"- with the two response options yes or no for each parent. Therefore, parental employment status was used to select adolescents living in households with no employed parent (this category included: both parents were unemployed; only the father was unemployed and they don`t have or see their mothers; only the mother was unemployed and they don`t have or see their fathers).

- $\quad$ Global Health Score (GHS): physical and psychological health were measured using a global health score developed by Ramos, Moreno, Rivera, and Pérez (2010), based on four indicators:

(1) life satisfaction, which is a measure created by the HBSC based on the "Cantril Ladder Scale" (Cantril 1965); (2) heath-related quality of life, evaluated by the instrument "KIDSCREEN-10 index" (Ravens-Sieberer and The European Kidscreen Group 2006); (3) selfreported health, evaluated using only one item in which the adolescents were asked how they 
considered their health to be at the present time (Idler and Benyamini 1997); and (4)

psychosomatic complaints, measured by the HBSC-symptom checklist (Ravens-Sieberer et al. 2010), which combines two sub-scales: psychological symptoms and somatic symptoms. Therefore, the Global Health Score is composed of 20 items which result in a single score (Cronbach's alpha: 0.884). This measure has demonstrated its unidemensionality, as well as good psychometric properties $(\mathrm{NNFI}=0.985, \mathrm{CFI}=0.995, \mathrm{RMSEA}=0.03)$ that are detailed in Ramos et al. (2010), and showing similar fit indices in other countries (Ramos et al. 2012).

Secondly, the following variables related to the participants, their families, and school context were used as independent variables:

\section{Sociodemographic factors:}

Individual level:

- Sex: boys and girls.

- $\quad$ Age: $11-12,13-14,15-16$ and 17-18 years old.

Family level:

- Parental education level: the education level of both fathers and mothers was considered and scored on 3 levels, the minimum level being never studied or basic studies and the maximum representing university studies.

- Subjective perception of family wealth: evaluated by the question: "How rich or wealthy do you think your family is?". This measure has been used in the HBSC study since 1994 as an indicator of the adolescents' perceived family economic status. The five response options were: 1 (poor), 2 (not very poor), 3 (normal), 4 (rich) and 5 (very rich). Due to the characteristics of the sample selected for this study, the frequency of adolescents who perceived their families as rich or very rich was extremely low $(n=28,3.1 \%)$, therefore the responses were classified into only two categories: 1 (poor, not very poor) and 2 (normal, rich or very rich).

- Family structure: assessed by asking the adolescents to indicate what adults live in the household where they spend most of their time. This measure has been employed in the HBSC survey since 2002, and later revised in 2006, 2010 and 2014 (Moreno and HBSC Family Culture Focus Group 2005). Response options were classified into four family-categories: two-parent families, singleparent families, stepfamilies, and other families.

School level: 
- Type of school: public or private.

- Habitat: urban or rural.

\section{Contextual variables:}

Family context:

- Perceived family support: assessed using the family subscale of the Multidimensional Scale of Perceived Social Support (MSPSS; Zimet et al.1988). This scale consists of four items related to the family such as: "I can tell my parents about my problems" or "I get the emotional help and support I need from my family". Answers are marked on a 7-point Likert scale, ranging from 1 (strongly disagree) to 7 (strongly agree). Responses were averaged to provide an overall score of family support. Alpha reliability for the 4 -item scale was .87 indicating good internal consistency . The Cronbach's coefficient alpha was .93.

- Satisfaction with family relationships (Moreno and HBSC Family Culture Focus Group 2005): this variable assesses the adolescents' satisfaction with their family relationships and was adapted from the Cantril Ladder (Cantril 1965): "In general, how satisfied are you with the relationships in your family?" with values from 0 (We have very bad relationships in our family) to 10 (We have very good relationships in our family).

Friend context:

- Perceived friend support: assessed using the friend subscale of the Multidimensional Scale of Perceived Social Support (MSPSS, Zimet et al. 1988). This scale consists of four items such as: "My friends really try to help me?" or "I can count on my friends when things go wrong". Answers are marked, a 7-point Likert scale from 1 (strongly disagree) to 7 (strongly agree). The mean score was calculated to provide an overall score for perceived friend support. Cronbach's coefficient alpha of this subscale was .85 , showing good internal consistency. In this study, the value of Cronbach's alpha was .94.

- Friends satisfaction: this variable measured adolescents' satisfaction with their friendships and was adapted from the Cantril Ladder (Cantril 1965), with the response options ranging from 0 ( $I$ have the worst possible relationship with my friends) to 10 (I have the best possible relationship with my friends).

School context: 
- Classmate support and teacher support: measured by means of two scales that were originally developed and validated by the international HBSC network (Torsheim et al. 2000), and have been revised to include the latest improvements in 2014 HBSC protocol. Classmate support consisted of a scale of three items such as: "The students in my class(es) enjoy being together". Teacher support also included three items such as "My teachers are interested in me as a person". Both scales are answered on a 5-point Likert scale from 1 (strongly agree) to 5 (strongly disagree). The scales have a high internal reliability with a Cronbach's alpha of .74 for classmate support and .82 for teacher support (Rasmussen et al. 2013). In this study the values were similar, showing a Cronbach's alpha of .77 and .83 respectively.

- Feelings toward school: assessed by the question "How do you feel about school?" and coded into four categories of responses ranged from 0 (I don't like it) to 3 (I like it a lot).

The variables family support, friend support, satisfaction with family relationships, satisfaction with friend relationships, and the perceived classmates support and teacher support, were coded as low, medium and high using terciles by means of the Extreme Groups Approach (Preacher et al. 2005). The Multidimensional Scale of Perceived Social Support (MSPSS) has been used in a previous study dividing their scores into terciles (Smith et al. 2015). Terciles were calculated following the distribution of these variables in the total representative sample of Spanish adolescents. Family support and friend support were coded as low $\leq 5.5$, medium $5.6-6.99$ and high $\geq 7$; satisfaction with family and friend relationships were coded as low $\leq 8$, medium $9-10$ and high $\geq 11$; and finally, classmate and teacher support were coded as low $\leq 3.5$, medium 3.51- 4.32 and high $\geq 4.33$. Tercile scores from the variables showed significant $(p \leq .001)$ and strong correlations with the continuous scores of the same variable: family support $\left(r_{s}=.92\right)$; friend support $\left(r_{s}=.94\right)$; family and friend satisfaction $\left(r_{s}=.97\right)$; and classmate and teacher support $\left(r_{s}=.93\right)$. Three categories were considered for the variable feelings towards school: 0 (adding the responses "I don't like school at all" and "I don't like school very much", which grouped the lower percentages of adolescents into one category, $11.6 \%$ and $22.7 \%$ respectively), 1 (I like school a bit) and 2 (I like school a lot).

\section{Procedure}

Data was collected through an online questionnaire following HBSC guidelines (Inchley et al. 2016): adolescents must respond to the questionnaire themselves; the anonymity and confidentiality of their 
responses must be guaranteed; and the questionnaire must be administered at school. The HBSC study was authorized by the Ethical Research Committee of the University of Seville and the Spanish Ministry of Health, Social Services and Equality (Moreno et al. 2016b). Informed consent was obtained from the schools, legal guardians and the students themselves.

\section{Statistical analysis}

Statistical analyses were conducted using IBM SPSS Statistics 22.0. In the first subsection of the results, descriptive statistics of the categorical variables are described as percentages and Pearson chi-square $\left(\chi^{2}\right)$ was used to compare the two groups of adolescents (resilient and maladaptive), in all the independent variables. Crammer's $V$ was also calculated to assess the effect size of the differences among groups.

In the second subsection, binary logistic regression was performed to analyze the likelihood of being resilient according to the predictors variables. The GHS was used as dependant variable, comparing maladaptive adolescents (those in the lowest GHS tercile) to resilient adolescents (those in the highest GHS tercile).

As predictors, 6 blocks of variables were entered into the model (sociodemographic variables at individual, family, and school level, and contextual variables related to the quality of family, peer and school contexts) to identify the principal contributors to high health-scores despite not having any employed parent. The predictive capacity of each set of variables was calculated using the Nagelkerke $R^{2}$ and a final model including all the considered variables is presented. Statistical significance was set at $p<$ 0.05. Results are presented using Odds Ratios (OR) and 95\% Confidence Interval (CI). An OR above 1 suggests a higher likelihood of being resilient, and below 1 a higher likelihood of falling in the maladaptive group.

Missing values were included as a category of the dependant variable, comparing adolescents that presented missing values with those adolescents included in the study who presented valid values for the examined variables. Analysis showed no differences, therefore, bias related to missing values is not a problem in this research.

\section{Results}

Comparisons among maladaptive and resilient adolescents 
In the first part of the results section, the two groups of adolescents with no employed parent were compared: resilient group, those with the highest GHS (290 adolescents in the upper tercile) and risk for maladaptive group, those with the lowest GHS (618 adolescents in the lower tercile). Table 1 shows the distribution of the maladaptive and resilient groups in all the variables analyzed.

Influence of sociodemographic factors. Table 1 shows that there was a greater proportion of resilient boys and younger adolescents aged 11-12 and 13-14 years old $\left(\chi^{2}(3)=169.16, p<.001\right)$, than girls and older adolescents aged 15-16 and 17-18 years old. The differences were small $(V=.17)$ regarding sex and moderate in the case of age $(V=.47)$.

With respect to family factors, there were no differences between the groups regarding the father's education level, however there were significant differences concerning the mother's education level. Specifically, the resilient adolescents showed a higher proportion of mothers with a high education level than the maladaptive group, despite the fact that these differences presented a small effect size $(V=.12)$.

There were significant differences between maladaptive and resilient adolescents with respect to perceived family wealth and family structure. Resilient adolescents tended to come from two-parent families and perceive their family wealth as normal, rich or very rich, and meanwhile maladaptive adolescents showed a greater proportion of single-parent families and tended to perceive their families as poor or very poor. However differences were small in both cases $(V=.24$ and $V=.14$ respectively).

Attending to school characteristics, there were no differences regarding the type of school, public or private. Despite the fact that more resilient adolescents were found in rural areas, the differences had a negligible effect size $(V=.08)$.

Influence of the contextual variables. There were significant differences in all variables related to the family, peer and school contexts between adolescents in the upper and lower terciles of the GHS. Table 1 shows that resilient adolescents presented higher perceived support from the family, friends, classmates, and teachers. In addition, these adolescents presented higher levels of satisfaction with their families and friends, and tended to like school more than the maladaptive adolescents. Almost all the differences were moderate except for friend support and family satisfaction, which showed small and large effect sizes, respectively.

Factors predicting health in adolescents with unemployed parents 
The second subsection focuses on the resilient group, which this study considers to those adolescents who despite not having any employed parent showed a high health score (upper tercile represented by $31.82 \%$ of adolescents with unemployed parents). This group was compared with the maladaptive group, those adolescents with no employed parent who showed low health scores (lower tercile of health represented by $68.06 \%$ of adolescents with unemployed parents). The results of the logistic regression analyses, using the resilient group as the reference, are shown in Table 2.

The final model includes all variables analyzed, showing a $68 \%$ predictive capacity with $93.9 \%$ of maladaptive and $77.9 \%$ of resilient adolescents correctly classified.

Sociodemographic factors. At the individual level, girls were less likely to be resilient than boys $(O R=0.208 ; 95 \% C I=0.125-0.346)$. With respect to age, $15-16$ year old $(O R=0.216 ; C I=0.097$ $0.480)$, and $17-18$ year old $(O R=0.143 ; C I=0.064-0.320)$ adolescents were more likely to be in the maladaptive group than the younger adolescents (11-12 years old). There were no significant differences between 11-12 year old and 13-14 year old adolescents.

Attending to the family, adolescents whose fathers had a high education level were more likely to fall into the maladaptive group $(O R=0.123 ; 95 \% C I=0.047-0.319)$, whereas having mothers with a high education level showed a high OR, reaching $7.029(C I=3.073-16.082)$, meaning that those adolescents with mothers with a high education level have the highest likelihood of being resilient. In addition, adolescents who perceived their family as poor or very poor showed more probability to be in maladaptive group $(O R=0.446 ; C I=0.253-0.785)$. No significant differences were found related to family structure.

With regards to type of school and habitat, only the type of school was significant, showing adolescents from private schools as being more likely to be maladaptive $(O R=0.577 ; C I=0.339-0.982)$ than the adolescents attending public schools.

Contextual factors. With respect to the contextual variables, family context showed the highest predictive capacity. Those adolescents who reported high perceived social support from their families $(O R=2.337 ; C I=1.297-4.214)$ and high family satisfaction $(O R=3.056 ; C I=1.792-5.211)$ were more likely to be resilient, whereas those with low social support from the family $(O R=0.522 ; C I=0.274$ $0.992)$ and low satisfaction with the family $(O R=0.259 ; C I=0.123-0.543)$ were more likely to be maladaptive compared to those adolescents with medium perceived support from their families and medium satisfaction with their families. 
Attending to peer variables, whereas perceived social support from friends was not significant, those adolescents who had higher satisfaction with their friend relationships were more likely to be resilient $(O R=3.118 ; C I=1.605-6.060)$ whereas those with low satisfaction with their friends were more likely to fall into the maladaptive group $(O R=0.426 ; C I=0.218-0.831)$.

Finally, regarding school variables, while teacher support was not significant, those adolescents who liked school $(O R=2.560 ; C I=1.412-4.641)$ and perceive high support from classmates $(O R=$ 2.135; $C I=1.210-3.768$ ) showed a higher probability of being in the resilient group, whereas adolescents perceive low classmate support were more likely to be in the maladaptive group $(O R=0.493 ; C I=$ $0.265-0.918)$.

The variables that presented the highest protective function, and consequently significantly increased the health scores of those adolescents with unemployed parents, were mother's education level, which reached an OR of 7.03, followed in descending order by friend satisfaction, family satisfaction, liking school, family support, and classmates support.

\section{Discussion}

In the sample of adolescents living in households with no employed parent, the percentage of adolescent presenting low health scores reached $68.06 \%$. In consonance with previous findings, this indicates that parental unemployment is related to worse health outcomes in children and adolescents. For example, Reinhardt Pedersen and Madsen (2002) found that children (aged 2-17) living in families with no parent employed in the past six months presented more psychosomatic symptoms, chronic illness and lower wellbeing. Similar results were found in a later study demonstrating that these effects were stronger when both parents were unemployed than when only one parent was unemployed (Reinhardt Pedersen et al. 2005). In addition, parental unemployment has been found to be negatively related to other health measures such as adolescents' self-rated health (Sleskova et al. 2006; Frasquilho et al. 2017), life satisfaction (Kind and Haisken-DeNew 2012) or high risk of behavioral and emotional problems (Harland et al. 2002).

Analizing the sociodemograpic variables related to sex and age, boys and younger adolescents living in households with no employed parent showed better health scores than girls and older adolescents living in the same conditions. These results can be attributed to health differences related to age and sex, as has been shown in previous studies (Cavallo et al. 2006; Goldbeck et al. 2007). However, these 
differences might be increased by girls and older adolescents' hightened awareness of the consequences of unemployemnt. For example, whereas a previuous study found that unemployment was a predictor of depression in boys but not in girls (Kaltiala-Heino et al. 2001), other studies -consistent with the present findings- have found parental unemployment to have a higher impact on adolescent girls than on boys (Fröjd et al. 2006; Bubonya et al. 2014; Frasquilho et al. 2017). Also in consonance with our results, other studies have shown parental unemployment to have worse health consequences for older adolescents (Frasquilho et al. 2017; Frasquilho et al. 2014). Moreover, Powdthavee and Vernoit (2013), examing the effect of parental unemployment on psychosomatic complaints among 11-15 year-olds, found that whereas parental job-loss even had a positive influence on the overall happiness of younger adolescents, this relationship dissapeared or turned negative in the older adolescents. One possible explanation to why older adolescents may suffer the consequences of parental unemployment more than their younger peers is because older adolescent have more cognitive capacity to understand the negative consequences of parental unemployment and are more able to value economic limitations (Frasquilho et al. 2017). In addition, older adolescents are closer to entering the labor market and may develop a more negative outlook of their own future employment (Schliebner and Peregoy 1994). In this regard Lim and Loo (2003) showed that parental unemployment has a negative effect on young people's self-efficacy and attitude towards work. However, it should be noted that the odds ratio for 15-16 year-old adolescents (OR $=0.216)$ was higher than for $17-18$ year-old adolescents $(O R=0.143)$, probably due to the lack of representativity for all the socieonocomic levels of this age group (given that education in Spain it is not mandatory for the older age group).

With regards to family-related variables, adolescents living in households with no employed parent did not show differences in health according to family structure. As has been previously demonstrated -and consistent with the results of the present research-, the quality of the family context is more important than the structure of the family context (Golombok 1998), as well as sociodemographic and contextual variables being important for the adjustment of children and adolescents (Oliva et al. 2014).

Although family structure was not a significantly strong predictor of resilience, adolescents living in single-parent families showed a higher impact of unemployment on health. Previous studies have reported that adolescents living in single-parent families show more negative effects of parental unemployent such as psychosomatic symptoms and chronic illness than those living in traditional families 
(Reinhardt Pedersen and Madsen 2002). Additionally job displacement of single mothers has been demonstrated to have significant negative effects on their children's educational achievement and sociopsychological wellbeing in young adulthood (Brand and Thomas 2014). A possible explanation for these results is that economic difficulties is one of the principal problems that single-parent families face (Morgado et al. 2003), thus leaving them more vulnerable to the effects of unemployment.

Interestingly, despite being unemployed, mothers with a high education level predicted higher levels of adolescent health scores, whereas unemployed fathers with high education levels increased the probability of their adolescent having a worse health score, thus being clasified as maladaptive. Previous research has found a relationship between the mother's education and adolescent health (Gakidou et al. 2010; Rahkonen et al. 1995), demonstrating to be a better predictor of adolescent health than other socioeconomic indicators such as father's education level, parental occupation or family material wealth (Moreno-Maldonado et al. 2017) and seems to be a risk factor in terms of their children's depressive and psychosomatic symptoms, and self-perceived health (Piko and Fitzpatrick 2007). A possible explination for these contradictory results for father's education level is that men with a high education level may have more difficulty dealing with the effects of unemployment. Certain cultural factors related to men and women's roles in the labor market and in the home could explain why men are more affected by job-loss than women (Artazcoz et al. 2004). In addition, a father's higher education level is a predictor of employment and income, and the effects of unemployment on adolescents have been demonstrated to be more significant when income loss is high compared to when income loss is low (Ortiz and Farrell 1993).

With respect to subjective socioeconomic status, it should be noted that since the sample consisted of adolescents living in households with no employed parent, a very small percentage (3.1\%) perceived their families as rich or very rich, and were therefore grouped with those adolescents who perceived their family wealth as normal. The results showed that adolescents who perceived their families as poor or very poor tended to present worse health than adolescents who perceived their family wealth as normal, rich or very rich. These results were expected since the association between parental unemployment and adolescents' perception of financial difficulties has been previously proven (Fröjd et al. 2006). In addition, prior studies have identified a relationship between subjective perception of wealth and adolescent health (Goodman et al. 2007; Elgar et al. 2016), influencing the severity of the impact of parental unemployment on adolescent health (Reinhardt Pedersen et al. 2005; Ström 2003). Additionally, 
a good financial situation before unemployment has demonstrated to act as protective factor for adolescent health (Bacikova-Sleskova et al. 2007).

The type of school and habitat showed moderate effects. Adolescents attending public schools were more likely to be resilient and presented better health than those attending private schools. Feeling poor in comparison to others could provoke negative psychological consequences such as stress (Wilkinson and Pickett 2006), and it is very likely that these consequences are more negative in adolescents who attend private school since their peer environment (within which they compare themselves) has economic resources. Although habitat was not significant, there were more resilient adolecents attending rural schools, and therefore probably living in rural areas.

Regarding the variables related to family, peer and school contexts, despite the fact that resilient adolescents showed a greater proportion of high perceived support from their families, friends, classmates and teachers, as well as higher levels of satisfaction with their families and friends, and more likelihood of liking school, not all the variables demonstrated to be significant predictors of resilience. Specifically, friend and teacher support did not show significant effects.

With respect to the role of friend relationships, only friend satisfaction proved to be a protective factor against the negative health consequences of parental unemployment. The fact that friend support did not show a significant effect can be explained because friend satisfaction was included simultaneously in the model and showed a more important effect for protecting adolescents from the negative impacts of parental unemployent on health than friends support. However in a previous study, friend satisfaction did not mediate the relationships between parental unemployment and adolescent health (Frasquilho et al. 2017). Nonetheless, in other research regarding social contacts in the context of employed or unemployed adolescents, the number of good friends and number of evenings spent with friends were found to decrease the impact of the adolescent's unemployment (Bacikova-Sleskova et al. 2007). These finding might suggest that friend relationships are important for reducing the impact of one's own unemployment, however the role of friends is less clear with regards to the parent's unemployment.

On the other hand, the fact that teacher support did not show a significant effect either might suggest a need to reinforce student-teacher relationships. In fact, Tummala-Narra and SathasivamRueckert (2013) found that teacher support was not related to adolescents' depressive symptoms, probably beause adolescents perceive their teachers as a source of academic support but not emotional support. However, classmate support and liking school showed significant effects in fostering resilience 
in adolescents living in households with no employed parent. To our knowledge, no research has reported the effect of classmate support or liking school on fostering resilience among adolescents who deal with parental unemployment. However, classmate support has been demonstrated to have a positive impact on adolescent health (Torsheim and Wold 2001; Due et al. 2003). Likewise, parental unemployment and job insecuirity have been related to poorer school achievement and academic performance in children and adolescents (Barling et al. 1999; Rege et al. 2011), as well as with a higher probability to repeat grades (Stevens and Schaller 2011) or lower probabilities of attending university (Coelli 2011).

Nonetheless, the role of the family was the most significant predictor of resilience among adolescents living in households with no employed parent, with both familly satisfaction and family support showing to be significant. Previous research have demostrated the important role that family support and family satisfaction have on adolescent health (Moreno et al. 2009; Collins and Laursen 2004; Jimenez Iglesias et al. 2015), with the family being the most important source of support for an adolescent's mental health (Helsen et al. 2000; Stewart and Suldo 2011), especially when families are under economic pressure (Williams and Anthony 2015). Moreover, the impact of unemployment on adolescent health has been atributed to the indirect effect of the parent-youth relationship (Frasquilho et al. 2016). In this sense, a positive family relationship can act as a protective factor against the negative effects of parental unemployment (Frasquilho et al. 2015; Bacikova-Sleskova et al. 2011; Willemen et al. 2011).

This research has the advantages of contemplating a large sample of adolescents and including a wide range of measures for analyzing factors that foster resilience in adolescents living in households with no employed parent. Moreover, the study was conducted in the context of an economic recession and in one of the countries with faster rising unemployment rates. Despite the fact that information about parental employment status was reported by the adolescents themselves, the information provided appear to be coherent with other data. The percentage of adolescents from the total representative sample who reported living in households with no employed parent was 5.4\%, consistent with 2014 national survey reports indicating that $9.61 \%$ of household (including all types of families and not only those with adolescents) have no employed members, (Encuesta de Población Activa, 2014). Moreover, this present research contributes to understanding the prevalence of resilience among adolescents. Results showed that $2.5 \%$ of the total sample were resilient adolesents with respect to $5.4 \%$ of the adolescents being exposed to the risk of living in households with no employed parent. Similarly, in a study carried out by Moreno et 
al. (2016a), the prevalence of resilient adolescents was $4.5 \%$ with respect to $13.4 \%$ being exposed to the same risk, which in the case of this study is atributed to having low-quality parent-child relationships.

However, some limitations should be taken into account. Firstly, the unemployment information collected for this study did not include measures that allow us to characterize the unemployment situation, such as the duration of unemployment -see reported differences between the effect of short- and longterm unemployment by Sleskova et al. (2006) and also a literature review by Ström (2003)- or the causes of unemployment -see the distinction between voluntary/endogenous and involuntary/exogenous causes of unemployment in (Kind and Haisken-DeNew 2012; Kassenboehmer and Haisken-DeNew 2008). In addition, we have no information about the family's perception of aide or other sources of financial help that might explain why 28 adolescents living in households with no employed parent reported that their families were rich or very rich. The role of government support for the unemployed and the posible perception of income-replacement benefits has been demonstrated to be effective in mitigating the effects of economic shocks on children's health (Institute of Health Equity UCL). Along the same lines, austerity measures adopted in many countries during the current economic crisis have reduced social protection, thus potentially increasing health inequalities (Karanikolos et al. 2013; Ortiz et al. 2011). Another limitation of this study is that is not possible to establish casual relationships due to the cross-sectional nature of the data. For example, other studies have found that children's poor health is a cause of parental unemployment and other factors that increase the risk of becoming unemployed (Kuhlthau and Perrin 2001).

In conclusion, increasing unemployment and changes in the labor market have a negative impact on adolescent health. As Olsson et al. (2003) indicated, each identied protective factors can define a focus of intervention, and therefore the results of this study have practical implications. This research showed the protective capacity of mother's education level, family support, satisfaction with family and friend relationships, classmate and teacher support and satisfaction with the school environment. In addition, interventions aimed at reducing the negative consequences of unemployment on adolescent health should consider gender inequalities, and the higher vulnerability of older adolescents, adolescents with a poor perception of their family's socioeconomic status, those whose fathers have a high education level.

\section{References}


Artazcoz, L., Benach, J., Borrell, C., \& Cortès, I. (2004). Unemployment and mental health:

Understanding the interactions among gender, family roles, and social class. American Journal of Public Health, 94(1), 82-88, doi:10.2105/AJPH.94.1.82.

Bacikova-Sleskova, M., Benka, J., \& Orosova, O. (2015). Parental employment status and adolescents' health: The role of financial situation, parent-adolescent relationship and adolescents' resilience. Psychology \& Health, 30(4), 400-422, doi:10.1080/08870446.2014.976645.

Bacikova-Sleskova, M., Geckova, A. M., van Dijk, J. P., Groothoff, J. W., \& Reijneveld, S. A. (2011). Parental support and adolescents' health in the context of parental employment status. Journal of Adolescence, 34(1), 141-149, doi:10.1016/j.adolescence.2010.01.003.

Bacikova-Sleskova, M., van Dijk, J. P., Geckova, A. M., Nagyova, I., Salonna, F., Reijneveld, S. A., et al. (2007). The impact of unemployment on school leavers' perception of health. Mediating effect of financial situation and social contacts? International Journal of Public Health, 52(3), 180187, doi:10.1007/s00038-007-6071-4.

Barling, J., Zacharatos, A., \& Hepburn, C. G. (1999). Parents' job insecurity affects children's academic performance through cognitive difficulties. Journal of Applied Psychology, 84(3), 437-444.

Baxter, J., Gray, M., Hand, K., \& Hayes, A. (2013). Parental joblessness, financial disadvantage and the wellbeing of parents and children. Department of Families, Housing, Community Services and Indigenous Affairs, Australia. https://www.dss.gov.au/sites/default/files/documents/03_2013/occasional_paper_48_final_lower_res_for_web.pdf

Bonanno, G. A. (2004). Loss, trauma, and human resilience: Have we underestimated the human capacity to thrive after extremely aversive events? American Psychologist, 59(1), 20-28.

Bonanno, G. A., Westphal, M., \& Mancini, A. D. (2011). Resilience to loss and potential trauma. Annual Review of Clinical Psychology, 7, 511-535, doi:10.1146/annurev-clinpsy-032210-104526.

Brand, J. E., \& Thomas, J. S. (2014). Job displacement among single mothers: Effects on children’s outcomes in young adulthood. American Journal of Sociology, 119(4), 955-1001.

Bubonya, M., Cobb-Clark, D. A., \& Wooden, M. (2014). A family affair: Job loss and the mental health of spouses and adolescents. IZA Discussion Papers, No. 8588.

http://hdl.handle.net/10419/106530. 
Buckner, J. C., Mezzacappa, E., \& Beardslee, W. R. (2003). Characteristics of resilient youths living in poverty: The role of self-regulatory processes. Development and Psychopathology, 15(01), 139162, doi: 10.1017.S0954579403000087.

Cantril, H. (1965). The pattern of human concerns. New Brunswick, NJ: Rutgers University Press.

Cavallo, F., Zambon, A., Raven-Sieberer, U., Torsheim, T., Lemma, P., \& HBSC Positive Health Focus Group (2006). Girls growing through adolescence have a higher risk of poor health. Quality of Life Research, 15(10), 1577-1585, doi:10.1007/s11136-006-0037-5.

Coelli, M. B. (2011). Parental job loss and the education enrollment of youth. Labour Economics, 18(1), 25-35, doi:10.1016/j.labeco.2010.04.015.

Collins, W. A., \& Laursen, B. (2004). Parent-adolescent relationships and influences. In R. M. Lerner, \& L. Steinberg (Eds.), Handbook of Adolescent Psychology (Vol. 2, pp. 331-362). New Jersey: John Willey \& Sons, Inc.

Conger, R. D., Conger, K. J., Elder, G. H., Jr., Lorenz, F. O., Simons, R. L., \& Whitbeck, L. B. (1992). A family process model of economic hardship and adjustment of early adolescent boys. Child Development, 63(3), 526-541, doi:10.1111/j.1467-8624.1992.tb01644.x.

Conger, R. D., Conger, K. J., \& Martin, M. J. (2010). Socioeconomic status, family processes, and individual development. Journal of Marriage and Family, 72(3), 685-704, doi:10.1111/j.17413737.2010.00725.x.

Conger, R. D., \& Donnellan, M. B. (2007). An interactionist perspective on the socioeconomic context of human development. Annual Review of Psychology, 58, 175-199, doi: 0.1146/annurev.psych.58.110405.085551.

Connor, K. M., \& Davidson, J. R. (2003). Development of a new resilience scale: The Connor-Davidson resilience scale (CD-RISC). Depression and Anxiety, 18(2), 76-82, doi:10.1002/da.10113.

DeCoster, J., Iselin, A.-M. R., \& Gallucci, M. (2009). A conceptual and empirical examination of justifications for dichotomization. Psychological Methods, 14(4), 349-366, doi:10.1037/a0016956.

Due, P., Lynch, J., Holstein, B., \& Modvig, J. (2003). Socioeconomic health inequalities among a nationally representative sample of Danish adolescents: The role of different types of social relations. Journal of Epidemiology and Community Health, 57(9), 692-698, doi:10.1136/jech.57.9.692. 
Elder, G. H. (1994). Time, human agency, and social change: Perspectives on the life course. Social Psychology Quarterly, 57(1), 4-15, doi:10.2307/2786971.

Elder, G. H., \& Caspi, A. (1988). Economic stress in lives: Developmental perspectives. Journal of Social Issues, 44(4), 25-45, doi:10.1111/j.1540-4560.1988.tb02090.x.

Elder, G. H., Nguyen, T. V., \& Caspi, A. (1985). Linking family hardship to children's lives. Child Development, 56(2), 361-375, doi:10.2307/1129726.

Elgar, F., McKinnon, B., Torsheim, T., Schnohr, C. W., Mazur, J., Cavallo, F., et al. (2016). Patterns of socioeconomic inequality in adolescent health differ according to the measure of socioeconomic position. Social Indicators Research, 127(3), 1169-1180, doi:10.1007/s11205-015-0994-6.

Encuesta de Población Activa (INE) (2014). Encuesta de Población Activa, primer trimestre de 2014. Madrid: Instituto Nacional de Estadística. Retrieved from http://www.ine.es/daco/daco42/daco4211/epa0414.pdf.

Fenton, C., Brooks, F., Spencer, N. H., \& Morgan, A. (2010). Sustaining a positive body image in adolescence: an assets-based analysis. Health \& Social Care in the Community, 18(2), 189-198, doi:10.1111/j.1365-2524.2009.00888.x.

Frasquilho, D., de Almeida, J. C., Gaspar, T., \& de Matos, M. M. N. G. (2014). Does age matter? Parental employment status influence on psychological well-being: findings from the national study of Portuguese schoolchildren. Revista de Psicologia da Criança e do Adolescente, 5(1), 57-71.

Frasquilho, D., de Matos, M., Marques, A., Gaspar, T., \& Caldas-de-Almeida, J. (2017). Factors affecting the well-being of adolescents living with unemployed parents in times of economic recession: Findings from the Portuguese HBSC study. Public Health, 143, 17-24, doi:10.1016/j.puhe.2016.10.003.

Frasquilho, D., de Matos, M. G., Marques, A., Neville, F. G., Gaspar, T., \& Caldas-de-Almeida, J. (2015). Unemployment, parental distress and youth emotional well-being: The moderation roles of parent-youth relationship and financial deprivation. Child Psychiatry \& Human Development, 47, 751, doi:10.1007/s10578-015-0610-7.

Frasquilho, D., de Matos, M. G., Neville, F., Gaspar, T., \& de Almeida, J. C. (2016). Parental unemployment and youth life satisfaction: The moderating roles of satisfaction with family life. Journal of Child and Family Studies, 25, 3214, doi:10.1007/s10826-016-0480-z. 
Friborg, O., Barlaug, D., Martinussen, M., Rosenvinge, J. H., \& Hjemdal, O. (2005). Resilience in relation to personality and intelligence. International Journal of Methods in Psychiatric Research, 14(1), 29-42, doi:10.1002/mpr.15.

Fröjd, S., Marttunen, M., Pelkonen, M., von der Pahlen, B., \& Kaltiala-Heino, R. (2006). Perceived financial difficulties and maladjustment outcomes in adolescence. European Journal of Public Health, 16(5), 542-548, doi:10.1093/eurpub/ckl012.

Gakidou, E., Cowling, K., Lozano, R., \& Murray, C. J. (2010). Increased educational attainment and its effect on child mortality in 175 countries between 1970 and 2009: A systematic analysis. Lancet, 376(9745), 959-974, doi:10.1016/S0140-6736(10)61257-3.

García-Moya, I., Brooks, F., Morgan, A., \& Moreno, C. (2015). Subjective well-being in adolescence and teacher connectedness: A health asset analysis. Health Education Journal, 74(6), 641-654, doi:10.1177/0017896914555039.

García-Moya, I., Suominen, S., \& Moreno, C. (2014). Bullying victimization prevalence and its effects on psychosomatic complaints: can sense of coherence make a difference? Journal of School Health, 84(10), 646-653, doi:10.1111/josh.12190.

Gili, M., Campayo, J. G., \& Roca, M. (2014). Crisis económica y salud mental. Informe SESPAS 2014. Gaceta Sanitaria, 28(Supp 1), 104-108, doi:10.1016/j.gaceta.2014.02.005.

Goldbeck, L., Schmitz, T. G., Besier, T., Herschbach, P., \& Henrich, G. (2007). Life satisfaction decreases during adolescence. Quality of Life Research, 16(6), 969-979, doi:10.1007/s11136007-9205-5.

Golombok, S. (1998). New families, old values: Considerations regarding the welfare of the child. Human Reproduction, 13(9), 2342-2347.

Goodman, E., Huang, B., Schafer-Kalkhoff, T., \& Adler, N. E. (2007). Perceived socioeconomic status: A new type of identity that influences adolescents' self-rated health. Journal of Adolescent Health, 41(5), 479-487, doi:10.1016/j.jadohealth.2007.05.020.

Harland, P., Reijneveld, S., Brugman, E., Verloove-Vanhorick, S., \& Verhulst, F. (2002). Family factors and life events as risk factors for behavioural and emotional problems in children. European Child \& Adolescent Psychiatry, 11(4), 176-184, doi:10.1007/s00787-002-0277-z. 
Helsen, M., Vollebergh, W., \& Meeus, W. (2000). Social support from parents and friends and emotional problems in adolescence. Journal of Youth and Adolescence, 29(3), 319-335, doi: 10.1023/A:1005147708827.

Idler, E. L., \& Benyamini, Y. (1997). Self-rated health and mortality: A review of twenty-seven community studies. Journal of Health and Social Behavior, 38(1), 21-37.

Inchley, J., Currie, D., Young, T., Samdal, O., Torsheim, T., Augustson, L., et al. (2016). Growing up unequal: Gender and socioeconomic differences in young people's health and well-being. Health Behaviour in School-aged Children (HBSC) study: International report from the 2013/2014 survey. Health Policy for Children and Adolescents. Copenhagen: WHO Regional Office for Europe.

Institute of Health Equity UCL. The Impact of the Recession and Welfare Changes on Health Inequalities. Resource document: https://www.instituteofhealthequity.org/themes/work-on$\underline{\text { recession-and-welfare-changes. }}$

Jimenez Iglesias, A. M., Moreno, C., García-Moya, I., \& López, F. (2015). Las relaciones familiares en la voz de chicos y chicas adolescentes. Revista de Psicologia da Criança e do Adolescente, 5(2), 11-30.

Kaltiala-Heino, R., Rimpelä, M., Rantanen, P., \& Laippala, P. (2001). Adolescent depression: The role of discontinuities in life course and social support. Journal of Affective Disorders, 64(2-3), 155 166, doi: Kaltiala-Heino, R., Rimpelä, M., Rantanen, P., \& Laippala, P. (2001). Adolescent depression: The role of discontinuities in life course and social support. Journal of Affective Disorders, 64(2-3), 155-166, doi:10.1016/S0165-0327(00)00233-0.

Karanikolos, M., Mladovsky, P., Cylus, J., Thomson, S., Basu, S., Stuckler, D., et al. (2013). Financial crisis, austerity, and health in Europe. The Lancet, 381(9874), 1323-1331, doi:10.1016/S01406736(13)60102-6.

Kassenboehmer, S. C., \& Haisken-DeNew, J. P. (2008). You're Fired! The Causal Negative Effect of Unemployment on Life Satisfaction. The Economic Journal, 119(536), 448-462, doi:10.1111/j.1468-0297.2008.02246.x.

Kearns, A., Whitley, E., Bond, L., Egan, M., \& Tannahill, C. (2013). The psychosocial pathway to mental well-being at the local level: Investigating the effects of perceived relative position in a deprived 
area context. Journal of Epidemiology and Community Health, 67(1), 87-94, doi:10.1136/jech2011-200415.

Kind, M., \& Haisken-DeNew, J. P. (2012). Unexpected victims: How parents' unemployment affects their children's life satisfaction. Working Paper No. 2/12. Melbourne Institute of Applied Economic and Social Research, The University of Melbourne.

Komarovsky, M. (2004). The unemployed man and his family: The effect of unemployment upon the status of the man in fifty-nine families. Walnut Creek, CA: Altamira Press.

Kuhlthau, K., \& Perrin, J. (2001). Child health status and parental employment. Archives of Pediatrics \& Adolescent Medicine, 155(12), 1346-1350, doi:10.1001/archpedi.155.12.1346.

Lim, V. K., \& Loo, G. L. (2003). Effects of parental job insecurity and parenting behaviors on youth's self-efficacy and work attitudes. Journal of Vocational Behavior, 63(1), 86-98.

Luthar, S. S., \& Cicchetti, D. (2000). The construct of resilience: Implications for interventions and social policies. Development and Psychopathology, 12(4), 857-885.

Luthar, S. S., Crossman, E. J., \& Small, P. J. (2015). Resilience and adversity. In R. M. Lerner, \& M. E. Lamb (Eds.), Handbook of Child Psychology and Developmental Science ( 7th Edition ed., Vol. Vol. III, pp. 247-286). New York: John Willey \& Sons, Inc.

Moreno, C., García-Moya, I., Rivera, F., \& Ramos, P. (2016a). Characterization of vulnerable and resilient Spanish adolescents in their developmental contexts. Frontiers in Psychology, 7, 983, doi:10.3389/fpsyg.2016.00983.

Moreno, C., \& HBSC Family Culture Focus Group (2005). Satisfaction with Family Relationships. In C. Currie (Ed.), Health Behaviour in School-aged Children. A WHO cross-national survey: Research protocol for the 2005/2006 survey. Document no published: University of Edinburgh.

Moreno, C., Ramos, P., Rivera, F., Jiménez-Iglesias, A., García-Moya, I., Sánchez-Queija, I., et al. (2016b). Los adolescentes españoles: estilos de vida, salud, ajuste psicológico y relaciones en sus contextos de desarrollo. Resultados del Estudio HBSC-2014 en España. Madrid: Ministerio de Sanidad, Servicios Sociales e Igualdad.

Moreno, C., Sánchez-Queija, I., Muñoz-Tinoco, V., Matos, M. G., Dallago, L., Bogt, T. T., et al. (2009). Cross-national associations between parent and peer communication and psychological complaints. International Journal of Public Health, 54(2), 235-242, doi:10.1007/s00038-0095415-7. 
Moreno-Maldonado, C., Rivera, F., Ramos, P., \& Moreno, C. (2017). Measuring the socioeconomic position of adolescents: A proposal for a composite index. Social Indicators Research, Online First, doi:10.1007/s11205-017-1567-7.

Morgado, B., González, M.M., \& Jiménez, I. (2003). Familias monoparentales: Problemas, necesidades y recursos. Portularia, 3, 139-163.

Mörk, E., Sjögren, A., \& Svaleryd, H. (2014). Parental unemployment and child health. CESifo Economic Studies, 60(2), 366-401, doi:10.1093/cesifo/ifu016.

Neppl, T. K., Jeon, S., Schofield, T. J., \& Donnellan, M. B. (2015). The impact of economic pressure on parent positivity, parenting, and adolescent positivity into emerging adulthood. Family Relations, 64(1), 80-92, doi:10.1111/fare.12098.

Oliva, A., Arranz, E., Parra, A., \& Olabarrieta, F. (2014). Family structure and child adjustment in Spain. Journal of Child and Family Studies, 23(1), 10-19, doi:10.1007/s10826-012-9681-2.

Olsson, C. A., Bond, L., Burns, J. M., Vella-Brodrick, D. A., \& Sawyer, S. M. (2003). Adolescent resilience: A concept analysis. Journal of Adolescence, 26(1), 1-11, doi:10.1016/s01401971(02)00118-5.

Ortiz, I., Chai, J., \& Cummins, M. (2011). Austerity measures threaten children and poor households: Recent evidence in public expenditures from 128 developing countries. Social and Economic Policy Working Paper. New York: UNICEF. https://www.unicef.org/socialpolicy/files/Austerity_Measures_Threaten_Children.pdf.

Ortiz, L. P., \& Farrell, M. P. (1993). Father's unemployment and adolescent's self-concept. Adolescence, 28(112), 937-949.

Paul, K. I., \& Moser, K. (2009). Unemployment impairs mental health: Meta-analyses. Journal of Vocational Behavior, 74(3), 264-282, doi: Paul, K. I., \& Moser, K. (2009). Unemployment impairs mental health: Meta-analyses. Journal of Vocational Behavior, 74(3), 264-282, doi:10.1016/j.jvb.2009.01.001.

Piko, B., \& Fitzpatrick, K. (2001). Does class matter? SES and psychosocial health among Hungarian adolescents. Social Science \& Medicine, 53(6), 817-830, doi:10.1016/S0277-9536(00)00379-8.

Piko, B., \& Fitzpatrick, K. (2007). Socioeconomic status, psychosocial health and health behaviours among Hungarian adolescents. European Journal of Public Health, 17(4), 353-360, doi: 10.1093/eurpub/ck1257. 
Powdthavee, N., \& Vernoit, J. (2013). Parental unemployment and children's happiness: A longitudinal study of young people's well-being in unemployed households. Labour Economics, 24, 253-263, doi:10.1016/j.labeco.2013.09.008.

Preacher, K., Rucker, D., MacCallum, R., \& Nicewander, W. (2005). Use of the extreme groups approach: a critical reexamination and new recommendations. Psychological Methods, 10(2), 178-192, doi:10.1037/1082-989X.10.2.178.

Rahkonen, O., Arber, S., \& Lahelma, E. (1995). Health inequalities in early adulthood: a comparison of young men and women in Britain and Finland. Social Science \& Medicine, 41(2), 163-171, doi:10.1016/0277-9536(94)00320-S.

Rajmil, L., Siddiqi, A., Taylor-Robinson, D., \& Spencer, N. (2015). Understanding the impact of the economic crisis on child health: the case of Spain. International Journal for Equity in Health, 14, 95, doi:10.1186/s12939-015-0236-1.

Ramos, P., Moreno, C., Rivera, F., Gaspar de Matos, M., \& Morgan, A. (2012). Analysis of social inequalities in health through an integrated measure of perceived and experienced health in Spanish and Portuguese adolescents. Journal of Health Psychology, 17(1), 57-67, doi:10.1177/1359105311406154.

Ramos, P., Moreno, C., Rivera, F., \& Pérez, P. (2010). Integrated analysis of the health and social inequalities of Spanish adolescents. International Journal of Clinical and Health Psychology, $10(3), 477-498$.

Rasmussen, M., Dür, W., Freeman, J., Currie, D., Klinger, D., Ramelow, D., et al. (2013). HBSC 2013 2014 Protocol. Section 2 part 3. Scientific rationales: 2.19 School setting. Unpublished manuscript.

Ravens-Sieberer, U., Erhart, M., Rajmil, L., Herdman, M., Auquier, P., Bruil, J., et al. (2010). Reliability, construct and criterion validity of the KIDSCREEN-10 score: a short measure for children and adolescents' well-being and health-related quality of life. Quality of Life Research, 19(10), 14871500, doi:10.1007/s11136-010-9706-5.

Ravens-Sieberer, U., \& The European Kidscreen Group (2006). The KIDSCREEN questionnairesQuality of life questionnaires for children and adolescents-Handbook. Lengerich: Pabst Science Publisher. 
Rege, M., Telle, K., \& Votruba, M. (2011). Parental job loss and children's school performance. The Review of Economic Studies, 78(4), 1462-1489, doi:10.1093/restud/rdr002.

Reinhardt Pedersen, C., \& Madsen, M. (2002). Parents' labour market participation as a predictor of children's health and wellbeing: a comparative study in five Nordic countries. Journal of Epidemiology and Community Health, 56(11), 861-867, doi:10.1136/jech.56.11.861.

Reinhardt Pedersen, C., Madsen, M., \& Köhler, L. (2005). Does financial strain explain the association between children's morbidity and parental non-employment? Journal of Epidemiology and Community Health, 59(4), 316-321, doi:10.1136/jech.2003.013839.

Rutter, M. (1999). Resilience concepts and findings: Implications for family therapy. Journal of Family Therapy, 21(2), 119-144, doi:10.1111/1467-6427.00108.

Schliebner, C. T., \& Peregoy, J. J. (1994). Unemployment effects on the family and the child: Interventions for counselors. Journal of Counseling and Development, 72(4), 368-372, doi:10.1002/j.1556-6676.1994.tb00951.x.

Sleskova, M., Salonna, F., Geckova, A., Nagyova, I., Stewart, R., van Dijk, J., et al. (2006). Does parental unemployment affect adolescents' health? Journal of Adolescent Health, 38(5), 527-535, doi:10.1016/j.jadohealth.2005.03.021.

Smith, N. R., Clark, C., Smuk, M., Cummins, S., \& Stansfeld, S. A. (2015). The influence of social support on ethnic differences in well-being and depression in adolescents: Findings from the prospective Olympic Regeneration in East London (ORiEL) study. Social Psychiatry and Psychiatric Epidemiology, 50(11), 1701-1711, doi:10.1007/s00127-015-1098-y.

Southwick, S. M., Bonanno, G. A., Masten, A. S., Panter-Brick, C., \& Yehuda, R. (2014). Resilience definitions, theory, and challenges: Interdisciplinary perspectives. European Journal of Psychotraumatology, 5, doi:10.3402/ejpt.v5.25338.

Stevens, A. H., \& Schaller, J. (2011). Short-run effects of parental job loss on children's academic achievement. Economics of Education Review, 30(2), 289-299, doi:10.1016/j.econedurev.2010.10.002.

Stewart, T., \& Suldo, S. (2011). Relationships between social support sources and early adolescents' mental health: The moderating effect of student achievement level. Psychology in the Schools, 48(10), 1016-1033, doi:10.1002/pits.20607. 
Ström, S. (2003). Unemployment and Families: A Review of Research. Social Service Review, 77(3), doi:10.1086/375791.

Tiet, Q. Q., \& Huizinga, D. (2002). Dimensions of the construct of resilience and adaptation among innercity youth. Journal of Adolescent Research, 17(3), 260-276.

Torsheim, T., \& Wold, B. (2001). School-related stress, support, and subjective health complaints among early adolescents: A multilevel approach. Journal of Adolescence, 24(6), 701-713, doi:10.1006/jado.2001.0440.

Tummala-Narra, P., \& Sathasivam-Rueckert, N. (2013). Perceived support from adults, interactions with police, and adolescents' depressive symptomology: An examination of sex, race, and social class. Journal of Adolescence, 36(1), 209-219, doi:10.1016/j.adolescence.2012.11.004.

Wagnild, G., \& Young, H. (1993). Development and psychometric evaluation of the Resilience Scale. Journal of Nursing Measurement, 1(2), 165-178.

Whitbeck, L., Simons, R. L., Conger, R. D., Wickrama, K., Ackley, K. A., \& Elder Jr, G. H. (1997). The effects of parents' working conditions and family economic hardship on parenting behaviors and children's self-efficacy. Social Psychology Quarterly, 60(4), 291-303, doi:10.2307/2787091.

Wilkinson, R. G., \& Pickett, K. E. (2006). Income inequality and population health: A review and explanation of the evidence. Social Science \& Medicine, 62(7), 1768-1784, doi:10.1016/j.socscimed.2005.08-036.

Willemen, A. M., Schuengel, C., \& Koot, H. M. (2011). Observed interactions indicate protective effects of relationships with parents for referred adolescents. Journal of Research on Adolescence, 21(3), 569-575, doi:10.1111/j.1532-7795.2010.00703.x.

Williams, L. R., \& Anthony, E. K. (2015). A model of positive family and peer relationships on adolescent functioning. Journal of Child and Family Studies, 24(3), 658-667, doi:10.1007/s10826-013-9876-1.

Zimet, G. D., Dahlem, N. W., Zimet, S. G., \& Farley, G. K. (1988). The Multidimensional Scale of Perceived Social Support. Journal of Personality Assessment, 52(1), 30-41, doi:10.1207/s15327752jpa5201_2. 
